Revista de Filosofía y Teoría Política, n. ${ }^{\circ}$ 48, 2017, e008, ISSN 2314-2553

Universidad Nacional de La Plata.

Facultad de Humanidades y Ciencias de la Educación.

Departamento de Filosofía

\title{
Lo político en Ernesto Laclau. Sobredeterminación y pluralidad en la constitución de las identidades políticas
}

\author{
The political in Ernesto Laclau. \\ Overdetermination and plurality in the constitution of political \\ identities
}

\section{Mariana Cané}

Instituto de Altos Estudios Sociales - Universidad Nacional de San Martín / CONICET, Argentina | cane.mariana@gmail.com

\section{PALABRAS CLAVE \\ Identidades políticas}

Sobredeterminación

Pluralidad

Poder

\section{RESUMEN}

Este trabajo rastrea la forma en que la noción de lo político es presentada en una selección de textos de Ernesto Laclau (“Hacia una teoría del populismo”; Hegemonía y estrategia socialista, "Nuevas reflexiones sobre la revolución de nuestro tiempo”, Emancipación y diferencia y La razón populista). El objetivo es detectar los significantes con los que dicha noción es articulada, los diferentes estatus que se le adjudican y sus vínculos con el binomio contingencia/necesidad. Se procura, así, ofrecer elementos que enriquezcan la teoría política del discurso como corpus analítico para la realización de estudios empíricos de procesos de constitución de las identidades políticas.

\section{KEYWORDS ABSTRACT}

Political identities

Overdetermination

Plurality

Power
This work tracks the way in which the notion of the political is presented in certain texts of Ernesto Laclau ("Towards a theory of populism”, Hegemony and Socialist Strategy, "New reflexions on the revolution of our time"; Emancipation(s) and On Populist reason.). The aim is to detect the signifiers with which this notion is articulated, different status that are awarded and their linkages to the binomial contingency/necessity. It seeks as well, to offer elements that enrich the political discourse theory as analytical corpus for empirical researches on the constitution of political identities

Cita sugerida: Cané, M. (2017). Lo político en Ernesto Laclau. Sobredeterminación y pluralidad en la constitución de las identidades políticas. Revista de Filosofía y Teoría Política, (48), e008. Recuperado de: http://www.rfytp.fahce.unlp.edu.ar/article/view/23142553e008 
A partir de su publicación, La razón populista (Laclau, 2009 [2005]) se ha erigido como matriz analítica de múltiples trabajos que abordaron diversos procesos de constitución de identidades políticas en general, y populistas en particular. Sin embargo, no consideraremos las definiciones provistas en ese texto como el punto cúlmine de "la obra" de Ernesto Laclau. Procuraremos, por el contrario, reivindicar el valioso aporte de otros de sus escritos para responder la pregunta por los mecanismos de constitución de las identidades políticas.

Sobre este horizonte, proponemos rastrear la forma en que se concibe, delimita y define la noción de lo político en cinco textos de Ernesto Laclau. Es necesario aclarar que la operación de lectura que se ofrece no parte de considerar el conjunto de textos como una unidad (una "obra" ${ }^{1}$ ) en donde sería posible identificar la evolución de un cierto núcleo de pensamiento. Más bien, de lo que se trata es de rescatar los modos de aparición de aquella noción en el interior de cada texto con el objetivo de identificar con qué otros elementos y cómo es articulada (entendiendo, por ello, que ambos aspectos delimitan una específica definición de lo político como noción polémica²). El corrimiento respecto del abordaje en términos de “obra” habilita, creemos, lecturas no lineales del conjunto de textos (a la vez que permite salir del corset que supone abordar cada texto como unidad coherente) para desarticular y rearticular las nociones ofrecidas por Laclau de maneras novedosas teóricamente, y empíricamente más productivas. Los escritos que abordaremos son: "Hacia una teoría del populismo”트 de 1977; Hegemonía y estrategia socialista. Hacia una radicalización de la democracia, de 1985, "Parte I. Nuevas reflexiones sobre la revolución de nuestro tiempo"쓰 de 1990; Emancipación y diferencia, de 1996 y La razón populista, de 2005.

Asimismo, procuraremos profundizar en algunos aspectos de la teoría política del discurso ${ }^{\underline{5}}$ no siempre atendidos y que, creemos, pueden enriquecer su uso como corpus analítico de casos empíricos. En esa línea, creemos posible identificar allí herramientas que la constituyan en sustento de análisis empíricos más dinámicos y atentos a la dimensión temporal de los procesos históricopolíticos $\underline{6}$.

\section{"Hacia una teoría del populismo". Dicotomía y clases}

En "Hacia una teoría del populismo", la forma de abordaje de lo político debe rastrearse a la luz del objetivo teórico que el texto propone: superar las imprecisiones que rodean los variados análisis del fenómeno populista y que impiden el “análisis científico de los fenómenos políticos” (Laclau, 1986, p. 166). Los ecos althusserianos de esta pretensión cientificista aparecen en forma contigua a un cierto "lenguaje tópico” (Althusser, 2008, p. 30) que concibe a lo social en clave topográfica y compuesto por diferentes “niveles”. El propio Laclau deja entrever las implicancias de esta lectura en una nota al pie que señala que pensar lo ideológico y lo político "como niveles[,] presenta una serie de dificultades”, para aclarar, acto seguido, que excede el desarrollo del texto trabajar sobre las mismas y afirmar que se retendrá así esta “denominación corriente” (Laclau, 1986, p. 185). A pesar de la aclaración -que no soslayamos-, podemos detectar que la decisión teórica aparece acompañada de una perspectiva específica de lo político. En esa línea, se define un primer nivel asociado al complejo ideológico-político -“superestructuras política e ideológica”(1986, p. 184)-, y un segundo, vinculado a lo económico (estructural) y signado por el modo y las relaciones de producción ${ }^{\underline{7}}$.El Laclau de este texto ${ }^{\underline{8}}$ que sostiene una distinción deudora de aquel lenguaje tópicoaspira, sin embargo, a distanciarse de aquellas perspectivas que denomina economicistas y 
superestructuralistas, ambas consideradas “igualmente reduccionistas” (1986, p. 185) respecto a la relación entre clase y superestructura.

La propuesta alternativa -es decir, la no reduccionista- que pretende ofrecer este Laclau se plasma en la distinción entre determinación y absorción: las clases (estructura) determinan a la superestructura política e ideológica, pero no la absorben "dentro de sí como momento necesario en el proceso de su autodespliegue” (1986, p.185). Por lo tanto, el nivel estructural (desarrollo de las fuerzas productivas) y la posición ocupada en relación a la propiedad de los medios de producción (clases, relaciones sociales de producción) determinan siempre y en última instancia (1986, pp. 185186) a la superestructura, pero de ello no se deriva que cada una lo haga de una forma en particular y específica que le sea inherente (es decir, de una forma que le "correspondería” a esa clase por ser esencialmente tal). Así, el modo en que existen las clases en el nivel superestructural o, lo que es lo mismo, lo que determina el carácter de clase de un complejo o conjunto ideológico, es la forma en que se articulan las interpelaciones y contradicciones que lo componen.

Desbrocemos entonces los elementos neurálgicos de este argumento. En primer lugar, encontramos que los complejos ideológicos (y podríamos agregar, políticos, dado que en varios pasajes aparecen como parte de aquel mismo nivel) implican articulaciones. Por un lado, éstas operan sobre la “materia prima” conformada por “contenidos" compuestos por prácticas, interpelaciones, contradicciones y "contenidos de un discurso" (1986, p. 189) $\underline{9}$. Por otro lado, se sostiene que dichas articulaciones incluyen contenidos clasistas y no clasistas, distinción clave que reconoce a cada componente diferentes estatus. Mientras los primeros responden a la contradicción central de clase en relación al lugar ocupado en el modo de producción (burguesía-proletariado, propiedad-no propiedad de los medios de producción), los segundos remiten a la contradicción pueblo-bloque de poder (es decir, que dependen del espacio ocupado en relación al Estado); esta doble referencia constituye la denominada “doble articulación del discurso político” (1986, p.195). Por su parte, la segunda contradicción -aquella que opone pueblo y bloque de poder-se observa en las "tradiciones populares”, las cuales se caracterizan por no ser “discursos coherentes y organizados” (1986, p. 195), por lo que sólo en articulación con discursos de clase pueden adquirir coherencia. El pueblo (y también lo popular) es presentado como un concepto de bajo grado de precisión, que "no va más allá del plano puramente alusivo o metafórico” (1986, p.192). Mientras que en algunos pasajes se afirma que "no es un mero concepto retórico, sino una determinación objetiva” (1986, p. 193), en otros, se define la posibilidad de que los “elementos popular-democráticos” (de los cuales el pueblo forma parte) permanezcan "en un mero nivel emocional y retórico, [no articulados como] totalidad coherente” (1986, p.214). Es decir que, a pesar de que el pueblo es una noción que "reviste una importancia decisiva en el análisis de toda coyuntura política” (1986, p. 193) y de que no tiene un estatuto meramente retórico, puede formar parte de discursos con sentidos "coherentes y

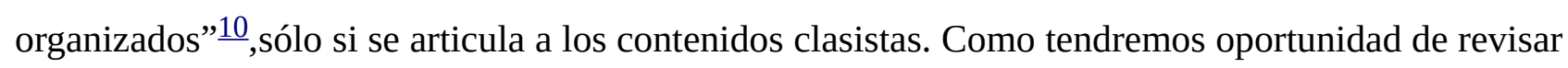
posteriormente, el estatuto de lo retórico y la capacidad explicativa del componente de clase serán dos de los aspectos de mayor contraste con los restantes textos de Ernesto Laclau (y aquel escrito en coautoría con Chantal Mouffe).

Señalaremos dos puntos más que distinguen a este escrito. En primer lugar, antagonismo, contradicción y diferencia -claramente diferenciados en Hegemonía y estrategia socialista- 
conforman aquí un esquema particular. Los dos primeros aparecen como conceptos asimilables, mientras que el tercero se distingue, al quedar vinculado a la lógica de construcción política del populismo de clase dominante (de lo cual se deduce, además, la distinción entre dos tipos de populismo -el de la clase dominante y el de la dominada-, justamente gracias al componente clasista). La clase dominante sólo puede articular al "pueblo" en su discurso neutralizando su conflictividad respecto al bloque de poder, precisamente porque lo presenta bajo la forma de diferencia no antagónica. Por otro lado, debemos destacar que tampoco “lo popular” y "lo democrático” aparecen aquí como instancias analíticamente diferenciadas. En este sentido, la “ideología popular-democrática” (1986, p. 199) está compuesta por un conjunto de interpelaciones que pueden ser presentadas de una forma peculiar que las convertiría en populistas. Retomaremos este punto más adelante, pero lo central aquí es destacar que populismo, popular y democrático no aparecen como elementos opuestos.

Esbozados los aspectos que consideramos más ricos para nuestro problema de estudio, nos adentraremos en un breve recorrido analítico. En primer lugar, consideramos que la noción de articulación (cercana a la de Gramsci $\frac{11}{11}$ ) y su potencialidad para pensar lo político permiten a este Laclau despegarse de ciertas formas del reduccionismo que se cuestionan en las primeras líneas del texto: los elementos que se articulan no tienen un contenido apriorístico o esencial de clase; su emergencia $\frac{12}{}$, por el contrario, queda signada por la forma de la articulación, es decir, por su relación con otros elementos $\underline{13}$. El problema es que aun cuando esta noción y los contenidos “no clasistas” abren el juego teórico y la lucha política (de clase y popular-democrática), ambos siguen fuertemente asociados a la estructura económica/de clase: el principio articulador es siempre de clase (a priori de ninguna en particular, pero sí de alguna $\underline{14}$ ) y lo “no clasista” mantiene su ligazón casi esencial a lo “clasista”, lo cual ocupa, además, un lugar “prioritario”트. En este sentido, decimos “casi esencial” - esencialista- porque, en varios pasajes, la posibilidad de la existencia de los componentes no clasistas al margen de los que sí lo son queda evidentemente puesta en duda: "la ideología democrática sólo existe articulada como momento abstracto de un discurso de clase"

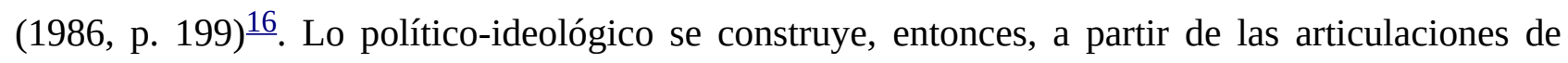
diversos elementos, y lo que le brinda unidad (es decir, lo que constituye su identidad-una) es un elemento de clase. Podríamos afirmar que lo político - desde esta perspectiva- no tiene una esencia clasista, pero sí de clases.

Por lo tanto, si bien se pretende dejar atrás una concepción reduccionista, al menos hasta aquí, este desarrollo teórico no parece reconocerle una especificidad propia, no derivada, a lo político. Y esto es así en tanto que -en última instancia-es la estructura la que brinda unidad y coherencia a todo fenómeno político (a nivel de la superestructura), por lo que su constitución queda determinada por una instancia que lo trasciende. Resta hacer, en este punto, una aclaración. Laclau señala que la construcción hegemónica (siempre de clase) no supone únicamente la imposición de una concepción del mundo, sino que implica la capacidad de una clase (grupo fundamental)de articularse con otras, “de forma tal que neutralice el potencial antagonismo de las mismas” (1986, p. 208) y logre que ellas compartan, acepten y hagan propia su cosmovisión. No podemos dejar de señalar que, si se entiende que la articulación permite la neutralización (o no) de un antagonismo $\frac{17}{}$, es porque las identidades de los elementos articulados se verían modificadas -en mayor o menor 
medida- por el proceso mismo de articulación. Sin embargo, el texto no parece desarrollar demasiado las potencialidades de esta propuesta.

Para finalizar el abordaje de "Hacia una teoría...”, revisaremos algunas cuestiones en torno a la definición del populismo que pueden ser de utilidad. Éste es definido como "la presentación de las interpelaciones popular-democráticas como conjunto sintético-antagónico respecto de la ideología dominante” (1986, p. 201). En este sentido, una "experiencia populista” se hace posible cuando una clase (o fracción de ella) precisa enfrentarse antagónicamente (1986, p. 202)con el bloque de poder para la construcción de su hegemonía: el elemento central de todo populismo es un antagonismo. Se ofrecen dos aristas analíticas más: por un lado, 1) las clases y el "pueblo" -como polos de dos contradicciones distintas- son "igualmente constitutivos del discurso político” (1986, p. 228), pero las primeras determinan el principio articulatorio, mientras que el segundo no; pero a pesar de esto, 2) la noción de pueblo "reviste una importancia decisiva en el análisis de toda coyuntura política" (1986, p. 193), en tanto "las clases no pueden afirmar su hegemonía sin articular al pueblo a su discurso” (1986, p. 230). Es así que la lucha hegemónica (política) queda íntimamente vinculada a la lucha por (la articulación de) el pueblo, ya sea para intentar neutralizar el antagonismo que supone con el bloque de poder, como para radicalizarlo, lo que dependerá de a qué discurso clase se articule (dominante y dominada, respectivamente). El populismo queda, entonces, profundamente imbricado con la lucha hegemónica, en tanto constituye "una inflexión particular de las interpelaciones populares” (1986, p. 228), a pesar de que se afirme que el pueblo no puede constituir el principio articulador central del discurso político. Por último, no podemos dejar de señalar que "en la medida en la que la resistencia popular se ejerce contra un poder externo y opuesto al pueblo, es decir, contrala forma misma del Estado, la resolución de la contradicción pueblo/bloque de poder sólo puede consistir en la supresión del Estado” (1986, pp. 230-231). Este momento se identifica con el socialismo si se lo entiende como un tiempo-espacio de constitución de una sociedad plena, lo que implica que el antagonismo se concibe como potencialmente erradicable.

\section{Hegemonía y estrategia socialista. La sobredeterminación y lo múltiple}

En Hegemonía y estrategia socialista(de aquí en adelante HYES), la cuestión de lo político presenta notorias divergencias respecto del caso anterior. Un primer aspecto se vincula con la distinción entre "la política” y “lo político”. Este abordaje, conocido como diferencia política(Marchart, 2009), supone que mientras la primera se compone de aquel conjunto de prácticas ónticas asociadas a lo que usualmente denominamos política ${ }^{18}$, el segundo se erige como instancia fundacional de todo orden. El enfoque propuesto en este texto se funda, así, "en privilegiar el momento de la articulación política, [de modo que] la categoría central del análisis político es (...) la hegemonía” (Laclau y Mouffe, 2010, p. 10). Y si bien en "Hacia una teoría del populismo" encontramos que hegemonía y articulación tenían un rol relevante, aquí lo político se corre del lugar de la superestructura ("subordinada a la lucha de clases" (Laclau, 1986, p. 199)para pasar a ser una instancia constitutiva de toda objetividad.

Laclau y Mouffetrazan como primer objetivo la deconstrucción de un conjunto de nociones althusserianas y gramscianas $\frac{19}{}$, lo que nos permite, ya desde el inicio, establecer un amplio espectro 
de puntos de diálogo con “Hacia una teoría del populismo”. Por un lado, los autores buscan deshacerse del "último reducto esencialista” (Laclauy Mouffe, 2010, p. 104) en la definición de hegemonía de Gramsci, por el cual ésta quedaba reducida a un fundamento ontológico (en una última y, finalmente, decisiva instancia), que suponía que “[tenía] que haber siempre un principio unificante en toda formación hegemónica, y [que] éste [debía] ser referido a una clase fundamental” (2010, p. 103). Allí, el nivel económico-estructural -como sustrato racional de la historia- relegaba lo político al estatus de una categoría regional (un mero "nivel”), operando de la misma manera que señalamos en el texto de 1986.Pero mientras en el pasaje citado los autores sostienen que el "reducto esencialista" que debe ser cuestionado en los argumentos gramscianos es unidimensional, aquí sostenemos que el mismo debe ser desagregado en dos componentes, los cuales no se deducen necesariamente uno del otro. Por un lado, encontramos que hay a) un principio unificante de la formación hegemónica y, por el otro, se afirma que b) dicho principio es de clase. Esta distinción es clave para poner en perspectiva nuestra pregunta en torno a la constitución de las identidades políticas: mientras el segundo (b) aparece como eje del argumento solamente en "Hacia una teoría...”, el primero pierde fuerza explicativa en HYES, pero cobra protagonismo en el antagonismo/frontera dicotómica pueblo-antipueblo de La Razón populista, de forma similar a como aparecía en la frontera de pueblo/bloque de poder de “Hacia una teoría...”. En este sentido, en estos últimos dos textos se concibe un espacio de lo social más dicotomizado y menos multiforme que el que se vislumbra en HYES.

Por otro lado, afirman que si, como se desprende del discurso althusseriano, no hay nada en lo social que no esté sobredeterminado, es porque lo social "se constituye como orden simbólico" (2010, p. 134). Si la sobredeterminación es entendida como "un tipo de fusión muy preciso, que supone formas de reenvío simbólico y una pluralidad de sentidos” (2010, p. 134), significa que ya no podemos pensar "la sociedad" como una totalidad cerrada, autorregulada y transparente, ni a las relaciones sociales como procesos parciales que encuentran en aquélla su fundamento último. Al no haber un sentido literal último -o, lo que es lo mismo, una estructura regida por una ley cuyo autodespliegue en la historia permita y funde las significaciones, unificando los contenidos y dotándolos de sentido-, lo social queda definido por su apertura, fragmentación y multiformidad (2010, p. 132), sin esencia que garantice la identidad ni de "la sociedad" ni de los sujetos sociales. Esta relectura de la categoría de sobredeterminación permite desligarla de la determinación esencial que le imponía la preeminencia “en última instancia” de la estructura económica que el Althusser de Ideología y aparatos... sostenía. Así, al no haber totalización esencial ni fronteras fijas entre los objetos, sólo quedan regularidades precaria e inestablemente fijadas: "hay una presencia de unos objetos en otros que impide fijar [y suturar] su identidad” (2010, p. 142). Pero esta deconstrucción tan productiva para el pensamiento de lo político se inscribe, a su vez, en una forma de pensar las lógicas relacionales originadas en el campo del análisis, tanto lingüístico como psicoanalítico $\underline{\underline{20}}$,que permite recurrir a nociones como metáfora, metonimia y desplazamiento, las cuales, a diferencia de lo que se argüía en "Hacia una teoría...”르, aquí se encuentran expandidas a todo el campo de lo social como lógicas constitutivas de su funcionamiento.

La eliminación de cualquier esencia o principio determinante (aun en última instancia) introduce en lo social la radical indeterminación de su fundamento (que ya no sería tal) y, por lo tanto, la imposibilidad de consolidarse como totalidad cerrada (y positiva, cuyos límites y unidad estarían 
dados a priori por la forma en la que se hubiera determinado su esencia). Esta apertura de lo social, sin embargo, no trae aparejado el abandono de la categoría de necesidad (lo que supondría la indeterminación total); lo que se disuelve es el espacio que hacía inteligible la distinción necesario/contingente como entidades positivas y externas entre sí, de forma tal que "la necesidad sólo existe como esfuerzo parcial de limitar la contingencia” y "lo contingente sólo existe en el interior de lo necesario" (2010, p. 154). Esta presencia de unos objetos dentro de otros es lo que Laclau y Mouffe definen como subversión, es decir, aquella "tensión irresoluble entre exterioridad/interioridad [que] es la condición de toda práctica social” (2010, p.151) e implica que no hay "interior” y "exterior" "puros” y ninguna dualidad está constituida por dos objetos “totales” con identidades suturadas esenciales (cf. exterioridad/interioridad, discursivo/extradiscursivo, momentos/elementos, etc. $)^{\frac{22}{2}}$. Al respecto, en varios pasajes subversión y sobredeterminación aparecen vinculadas en forma más o menos directa, por lo que es importante detallar en qué consiste estrictamente su diferencia. La subversión es presentada como aquel mecanismo que rige la relación entre lógicas opuestas o inversas $\frac{23}{}$, que supone la interrupción de unas por otras y que, por tanto, impide su “plena realización”. Por otro lado, la sobredeterminación emerge como una alternativa a la determinación unidireccional de un objeto por otro (su vínculo con la subversión aparece justamente aquí, dado que ésta es la que permite pensar que esos objetos no son esencialmente, no son unidades-cerradas): se da en un espacio en el que a) no hay dos, sino multiplicidad de objetos, por lo que b) la "determinación” se efectiviza en múltiples direcciones, es decir, de unos varios objetos sobre otros varios objetos, c) con un(os) sentido(s) de "ida y vuelta" entre ellos, mutuamente (múltiplemente en realidad, porque no es mutua-entre-dos) imbricados.

En conclusión, ambas nociones colocan el foco en la constitutiva multidimensionalidad tanto de lo social como de los procesos de constitución de las identidades. Es en el locus de aquellas tensiones donde se constituye lo social $\underline{24}$ entendido como campo de la discursividad que excede todo discurso y como terreno en el que se relacionan elementos de forma contingente, con la sobredeterminación de fijaciones identitarias precarias. Sólo allí es posible reflexionar sobre la articulación hegemónica como una construcción política (2010, p. 124), la cual implica "práctica[s] que establece[n] una relación tal entre elementos, [de forma] que la identidad de éstos resulta modificada como resultado de [aquéllas]” (2010, p. 142).Es así que gracias a la construcción de puntos nodales en torno a cadenas equivalenciales (de elementos subvertidos en su mera diferencialidad) se producen políticamente efectos de frontera antagónicos. Por otro lado, y en vínculo con ello, es la ya referida apertura de lo social la que permite que la articulación se opere sobre elementos que son significantes flotantes que no han cristalizado (ni podrán hacerlo nunca totalmente) en momentos (como parte plena de un todo); caso contrario, la práctica política sería pura repetición de identidades esenciales, cuya relación no sería de articulación (puesto que ésta transforma su identidad en y por el proceso que implica).La subversión, la sobredeterminación y, como veremos luego, la condición indecidible de toda estructura son el basamento conceptual que permite pensar la articulación política en aquel sentido.

El otro componente clave en esa serie conceptual es el antagonismo, en tanto es el que impide la sutura total y plena y que, a diferencia de otras relaciones (como la contradicción), no se da entre objetos previamente constituidos -como vimos en "Hacia una teoría..." $\underline{25}$, que ya son- 
esencialmente-(ver nota 24) identidades plenas. Es "la presencia del Otro [lo que] me impide ser totalmente yo mismo" (2010, p. 168), que me subvierte en mi identidad, aunque él tampoco puede constituirse totalmente como unidad-una. "El antagonismo constituye los límites de toda objetividad -que se revela como objetivación, parcial y precaria” (2010, p. 158)르르. Es la experiencia de la subversión de toda significación y, al mismo tiempo, aquello que la posibilita, al detener el desplazamiento de sentidos entre significantes diferenciales. Pero también, al ubicarse en sus límites, se vuelve inaprehensible por el lenguaje (como discurso- sistema de posiciones diferenciales), puesto que éste "sólo existe como intento de fijar aquello que el antagonismo subvierte” (2010, p. 169). El antagonismo no es ni interior ni exterior a "la sociedad”, constituye sus límites -los cuales son siempre precarios-, pero desde “adentro” de la misma, penetrándola, subvirtiéndola (impidiendo su objetividad, pero no cierta objetivación, por más precaria que ésta sea).

Por último, el aspecto propositivo del texto en relación con la práctica política ofrece algunas particularidades significativas. Las luchas hegemónicas en el contexto de las sociedades industriales avanzadas deben orientarse hacia la construcción de una democracia radical (como tarea política de la izquierda) o, lo que es lo mismo, deben propender a la multiplicación de efectos equivalenciales. Desechando el “carácter fundacional”르 (2010, p. 223) que suponía el hecho revolucionario “tradicional”, Laclau y Mouffe retoman aquí la multidimensionalidad que la práctica de la guerra de posición implicaría si fuera pensada -como ellos proponen- en un espacio social abierto. Aquel carácter fundacional estaba dado por la definición de un punto de ruptura privilegiado (revolución) desde el que se planteaba la reconstrucción de la sociedad, mientras que, por el contrario, la lucha emancipatoria de “carácter procesual” (2010, p. 223) es proclive a la producción de múltiples puntos de ruptura y la lucha en el marco de diferentes espacios políticos. Esto último sólo sería posible si se comprende que la dicotomización del espacio social es resultante de efectos de articulación hegemónica y no ya un dato a priori (como se podía desprender, por ejemplo, de los escritos de Gramsci). En HYES, por tanto, se distingue entre luchas democráticas -que suponen una pluralidad de espacios políticos- y luchas populares -que se asocian a discursos que construyen un espacio político tendencialmente dividido en dos campos-. La apuesta política por la democracia plural y radical que se pregona en este texto lleva a la siguiente afirmación: “está claro que el concepto fundamental es el de 'lucha democrática' y que las luchas populares sólo constituyen coyunturas específicas, resultantes de una multiplicación de efectos de equivalencia entre las luchas democráticas” (2010, p. 181) . A diferencia del texto de 1977 (y, como veremos luego, también en contraposición al de 2005, dado que en ambos prima una visión dicotomizada de la emergencia de las identidades políticas), aquí se apuesta a la proliferación de puntos de antagonismo como potenciales cuestionamientos de las relaciones de subordinación, puesto que esto favorece la profundización de la revolución democrática (2010, p. 207), siempre y cuando no se mantenga la mera reivindicación del particularismo y se logre una articulación hegemónica. Este es el

...terreno teórico a partir del cual la noción de democracia radicalizada y plural (...) encuentra las primeras condiciones de su aprehensión: es sólo si se acepta la imposibilidad de reconducir las posiciones de sujeto a un principio positivo y unitario fundante de las mismas, que el pluralismo puede ser considerado radical (2010, p. 211). 
La pluralidad de lo político, por tanto, supone que la lucha política no se da en un espacio único. Se politizan $\underline{28}$ todas las relaciones sociales. En tanto cualquier elemento puede emerger como sede de un antagonismo, no se descarta ningún espacio como potencialmente político (ni Estado, ni sociedad civil, ni el partido) ${ }^{\underline{29}}$. Se revela aquí la fuerza de la propuesta para la práctica política, a la vez que se abre un espacio rico para la comprensión y el estudio de los procesos históricos. Y esto es así, puesto que en esa misma línea se define el terreno en que se desarrolla la lucha política -en forma asimilable a la de lo social, aunque no se explicita el vínculo que hay entre ambos-, como aquel en que los espacios políticos se autonomizan y relacionan y que está constituido en parte por las luchas en esos espacios, en parte por las formaciones discursivas que han institucionalizado las varias formas de subordinación. Es justamente este espacio/terreno el que constituye la superficie de emergencia de todo objeto/objetivación y, por ende, de toda lucha política; y dado que, como ya se señaló, interioridad y exterioridad son siempre-ya mutuamente subvertidas, resulta evidente que ese terreno atravesado por lo institucionalizado/sedimentado, y por una diversidad de luchas, no puede ser meramente externo a lo que allí emerge, sino que lo sobredetermina radicalmente.

El hecho de que se aborde la institución de los límites de toda identidad social (y, finalmente, de toda objetividad) como algo no dado ni esencial, pero sobre todo como el espacio de una lucha intrínsecamente política, es lo que permite tomar distancia de una concepción de la política "en sentido restringido de reivindicaciones que se sitúan al nivel de los partidos y del Estado” (2010, p. 195), para introducir el pensamiento de la política como “creación, reproducción y transformación de las relaciones sociales [es decir como] el problema de la institución de lo social” (2010, p. 195). Como señalamos al inicio de este apartado, uno de los aportes clave de este texto $\underline{\underline{30}}$ para el pensamiento de lo político radica en la distinción entre la política (primera definición) como “gestión de la positividad social” (2010, p. 236)y lo político (segunda definición) como espacio de constitución de la objetividad social. Esta concepción de la diferencia política es la que introduce la posibilidad de la desregionalización de lo político $\underline{31}$.

Es posible, sin embargo, identificar dos acepciones de lo político. Una remite, insistimos, a la institución de lo social en un terreno siempre-ya atravesado por antagonismos, por lo que políticosocial-articulación-antagonismos son elementos de la misma cadena. Pero hay también una acepción (como adjetivo que define el carácter político de una lucha) que nos reenvía a pensarlo en relación a su objetivo y que lo asocia más directamente a lo que Laclau y Mouffe entienden como política democrática. Por un lado, el objetivo de toda lucha política (lo que le otorga el carácter político) es "la transformación de una relación social que construye a un sujeto en relación de subordinación” (2010, p. 195); se convierte esta subordinación en opresión, haciendo de ella la sede un antagonismo (2010. p 196) y permitiendo, finalmente, la desarticulación de esa relación y la expansión de la igualdad (porque de lo que se trata -finalmente- es de "luchar contra las desigualdades” (2010, p. 195) ). Pero, a la vez, la política democrática aparece asociada a la proliferación de aquellos antagonismos sobre los cuales sería posible construir/articular un nuevo sistema de equivalencias que hiciera inteligible lo social sobre la base de un ordenamiento distinto al vigente. La democracia radicalizada es "una forma de la política” (2010, p. 239), aquella que borra la posibilidad de aprehender el conflicto en una única clave de lectura, en términos de un “discurso unificado” (2010, p. 238): los diversos antagonismos y puntos de ruptura sobre los que se 
monta y que permiten su avance en la expansión de la igualdad conforman una diversidad, una discontinuidad discursiva que, dado su carácter múltiple, ya no pueden ser reconducidos a un punto privilegiado de quiebre. Queda, entonces, así conformada una cadena argumentativa diferente a la especificada líneas atrás, porque desde esta lectura deberíamos hablar de político-socialarticulación-antagonismos-rearticulación-democracia (radicalizada y plural, no la de tinte liberal asociada al individualismo posesivo y reticente a la construcción de instancias colectivas), que pone el foco no tanto en la articulación, sino en la ruptura que supone la transformación del statu quo de relaciones de subordinación $\underline{32}$. Finalmente, en ambas acepciones, el foco argumentativo se coloca en la multiplicidad asociada a lo político. Es este uno de los aspectos clave de la contraposición con la concepción de "Hacia una teoría del populismo" donde, como tuvimos oportunidad de ver, el conflicto se daba en torno a los antagonismos de clase (proletariado - burguesía) y pueblo - bloque de poder.

\section{Nuevas reflexiones $\underline{33}$. La reactivación de lo sedimentado en el tiempolespacio de la dislocación}

Las nociones centrales de este texto son las de dislocación (de toda identidad, en tanto un exterior amenaza siempre su constitución plena (Laclau, 2000, p. 55)) y la de antagonismo, concebido no solamente como "límite de toda objetividad" (2000, p. 34), sino también como "relación contingente de poder entre (...) dos polos” (2000, p. 24). Mientras la segunda noción mantiene fuertes puntos de contacto con las formulaciones de HYES, es la dislocación la que abre la puerta a los aportes fundamentales de Nuevas reflexiones para el pensamiento de lo político y su vínculo con un abordaje de la temporalidad en clave no teleológica y constitutivamente contingente. Es justamente en estas indagaciones en torno al estatuto del tiempo, donde las dinámicas de reactivación y sedimentación pueden ser concebidas.

Resulta más dificultoso identificar aquí la unidad mínima de análisis de la misma forma que en los otros escritos. El foco se coloca en el estatuto de las relaciones sociales, el sujeto, la estructura (o el todo social) y el tiempo $\underline{34}$. Se definen, así, dos características de las relaciones sociales (son contingentes y fundadas en relaciones de poder) que permiten concluir un tercer y fundamental aspecto: “la primacía de lo político sobre lo social” (2000, p. 50). Esta aseveración no sólo es nodal para nuestra clave de lectura, sino que ofrece también un fructífero basamento teórico para cualquier análisis de la empiria social y política (desde un estudio sobre movimientos sociales, hasta otro sobre el funcionamiento del sistema de partidos). Y aunque esta perspectiva no invalida la distinción analítica entre "lo social” y “lo político" (que permitiría afirmar, por ejemplo, que movimientos sociales y partidos políticos pertenecen a dos niveles diferenciados),sí exige que se la cuestione intentando identificar, en cada coyuntura, cómo se define su nexo y sus mutuas imbricaciones (es decir, no dándola por preconcebida).

Las potencialidades analíticas de la segunda de las referidas características se abordarán con mayor detalle en el estudio de Emancipación y diferencia, pero no podemos dejar de señalar que aquí también el poder retiene para sí una clara centralidad argumentativa. Las relaciones sociales "son siempre relaciones de poder" (2000, p. 48) porque la constitución de toda identidad es siempre un acto de represión de otras posibilidades alternativas (2000, p. 47), que se produce en el 
tiempo/espacio de otras tantas relaciones de poder que estructuran parcialmente lo social. Esto implica que el poder es inerradicable (2000, p. 52) y es ello lo que explica la indecidibilidad $\frac{35}{2}$ de la estructura, en tanto es solamente en la disputa política por el poder en donde surge la decisión. En conclusión, la objetividad (todo lo que hay) resulta de una decisión que "se constituye (...) como relación de poder” (2000, p. 47). Por su parte, es el sujeto el que se erige como locus de esa decisión (2000, p. 47); un sujeto que no es -al igual que en HYES-un mero agente de la estructura ni un puro individuo autocentrado.

Pero ¿qué significa que la estructura está dislocada? Al no estar completamente determinada por ninguna esencia ni por un desarrollo teleológico de la misma, la estructura es ella misma fallada $\frac{36}{\mathrm{y}}$ falla también en constituir al sujeto en forma plena. Y su vínculo con lo exterior es conflictivo porque su constitución como “una” unidad es contingente (es decir, podría haber sido “otra”). Ese exterior-otro (lo que ella no es, pero podría haber sido) la amenaza, porque la posibilidad de la mutación está siempre-ya presente. Es por ello que la dislocación cuenta con tres dimensiones: la temporalidad, la posibilidad y la libertad, y todas ellas tienen un carácter constitutivamente político.

Por otro lado, desde esta perspectiva, tiempo y espacio son opuestos exactos. Mientras este último supone la "repetición gobernada por una ley estructural de las sucesiones” (2000, p. 58), la temporalidad introduce un desajuste $\frac{37}{}$, una mutación: “la forma pura de la temporalidad $\frac{38}{y}$ y la forma pura de la posibilidad coinciden” (2000, p. 59). Pero esta posibilidad (la segunda característica de la dislocación) y la libertad (tercer componente) no son absolutas: todo es posible, pero no igualmente posible, porque la emergencia se produce en un espacio siempre-ya semiestructurado. El proceso de constitución de las identidades y sus relaciones o lo que es lo mismo, la constitución de la objetividad social, es un momento de exclusión de otras posibilidades.

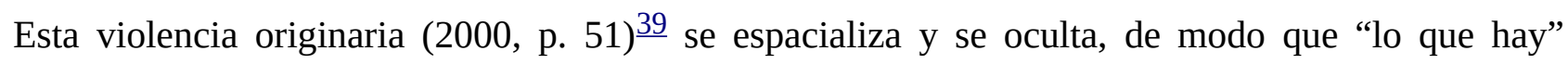
aparece naturalizado y sedimentado (como algo que es esencialmente y, por tanto, es todo lo que debe ser y no puede ser de otra manera). Esta sedimentación -efecto de relaciones de poder pretéritas- se reactiva en el momento del surgimiento de una identidad nueva, es decir, en el momento político por excelencia en el que la contingencia de todo origen se hace patente.

Dos puntos son clave aquí. La “diferencia política” (Marchart, 2009) adopta aquí nuevos ribetes, porque lo que se opone conceptualmente a lo político es lo social, vinculado a la sedimentación de prácticas y a la estructuración de instituciones e identidades. Lo político tiene primacía sobre lo social (2000: 50) porque lo constituye y se vincula específicamente a la dimensión antagónica, la lucha por el poder, la violencia originaria y la temporalidad. Pero, aunque se señala esa primacía, no se soslaya la mutua imbricación entre reactivación y sedimentación que, al igual que veremos en Emancipación y diferencia con la noción de subversión, procura aprehender el dinamismo y la no multidireccionalidad del nexo.

\section{Emancipación y diferencia. La desnivelación de lo social y el poder}

Emancipación y diferencia (EYD de aquí en adelante) y HYES encuentran en la preocupación por la emancipación un punto de conexión teórica y política. Y si bien en HYES se introduce la noción de significante flotante, es en “¿Por qué los significantes vacíos son importantes para la política?” 
(Laclau, 1996), donde se expone la potencialidad de los significantes vacíos para el problema que nos atañe. Se parte aquí también de la aprehensión de lo social como orden simbólico (significante), con eje en la tensión irresoluble entre las lógicas de la equivalencia y de la diferencia. Retomando algunas de las críticas realizadas en HYES a los postulados de Ferdinand de Saussure (en torno a la totalidad como posibilidad de todo proceso de significación), se afirma la necesidad de la concreción de una exclusión como la única forma de instituir un límite y, por ende, algo del orden de la totalidad. Los significantes vacíos (SV) son los que, al anularlas simples diferencias por la institución de un antagonismo con una alteridad, permiten aprehender aquel límite.

Un primer elemento de relevancia es la unidad de análisis sobre la que se enfoca EYD. No son aquí las luchas -como en HYES- ni las demandas -como en LRP-. Sin intentar reconstruir un supuesto sentido oculto en el uso de estos conceptos, creemos que estas divergencias dicen algo sobre la forma en que la cuestión de la constitución de las identidades políticas es abordada en cada caso. Presentaremos algunas posibles líneas de análisis al respecto, sin pretender en forma alguna agotarlas.

Mientras que tanto una lucha que se realiza contra alguien/algo (por alguna razón/reivindicación), como una demanda que se realiza a alguien/algo (de algo de lo que se requiere), parecen traer aparejada una referencia a un otro conflictivo ("contra el/lo que” se lucha, "al que” se demanda algo), se hace más difícil avizorar esta dimensión en el caso de las unidades significativas. Éstas parten de un esquema de análisis lingüístico saussureano y parecen remitir, más bien, a una lógica relacional (que no reviste necesariamente un aspecto conflictivo) y a la que puede atribuirse un aspecto más formal (o formalista). Su articulación con el rol argumentativo de las relaciones de poder matizará dicho aspecto.

Por otro lado, en vínculo con el estatuto del límite, el fenómeno de la subversión detenta un lugar clave en el argumento de EYD, porque es justamente lo que permite comprender el proceso por el que las unidades significativas "se vacían de todo vínculo con significados particulares y asumen el papel de representar el puro ser del sistema” (1996, p. 75). Encontramos, entonces, una unidad significativa que debe vaciarse de sus contenidos particulares anulando su condición diferencial $\underline{40}$ para poder encarnar en sí a la totalidad imposible del sistema en que significa. Pero si ninguna unidad está determinada a priori para cumplir este rol (puesto que no hay esencia alguna que garantice ni la totalidad ni ningún proceso que se lleve a cabo en el espacio social), “¿qué es lo que determina que sea una y no las otras la que encarna, en momentos históricos particulares, esta función universal [del significante vacío]”? (1996, p. 76). Es decir, si la emergencia es radicalmente contingente, ¿cómo se desentraña este proceso? La respuesta, sostiene el Laclau de EYD, se aloja en el vínculo entre los significantes vacíos y la política.

La centralidad que le otorgamos a este texto radica en la forma en que se resuelve justamente esta pregunta. Aquí, el carácter desnivelado, desigual (1996, p. 76) de la superficie social en que se produce la emergencia de significantes vacíos se erige como un aspecto primordial del análisis. De forma similar a NR, en EYD se resalta que aquella superficie social está siempre-ya atravesada por los efectos de procesos resultantes de luchas políticas pretéritas y por las relaciones de poder. A causa de esto, se explicita que, si bien cualquiera puede, "no toda lucha es igualmente capaz de transformar sus contenidos en un punto nodal que pueda tornarse un significante vacío” (1996, p. 
81). Hay $\underline{41}$ puntos de alta concentración de poder en los que las lógicas de la equivalencia y la diferencia -en cuya tensión se juega aquella emergencia- se sobredeterminan entre sí. El poder (que en este texto y en NR es un factor de alta importancia, a diferencia de lo que sucede en los restantes) atraviesa lo social y su principal característica es no estar equitativamente distribuido. En ese contexto, la operación hegemónica que supone la construcción de identidades políticas en torno a un SV se da en un terreno en el que ya previamente se realizaron otras operaciones hegemónicas, que dieron como resultado una relativa estructuración de lo social donde "las relaciones entre grupos se constituyen como relaciones de poder” (1996, p. 54). Este último elemento es central, porque de lo que hablamos aquí es de diferencias (entre grupos) que no son "neutrales": la diferencia se constituye siempre en base a una exclusión. Lo social no es complejo solamente a raíz de la multiplicidad (como se dejaba ver en HYES), sino también a causa de esta desigual distribución del poder entre los grupos, que supone exclusión y subordinación de unos por otros y que sólo puede ser comprendida si se introduce la dimensión histórico-temporal en el argumento. Así, emancipación y poder mantienen una relación indecidible; si emancipación supone un corte radical con el poder, éste es -simultáneamente- su condición de posibilidad (puesto que aquélla sólo puede darse en el terreno desnivelado de lo social).

Lo político se da en ese terreno desnivelado y, además, atravesado y constituido por dicotomías parciales y precarias (1996, p. 37): es la multiplicidad y no "la subordinación a una frontera única” (1996, p. 37) la que define lo social. La preocupación política por la emancipación está presente, al igual en que en HYES, pero tampoco aquí se la concibe en torno a una localización estructural sobre la que se montaría una única frontera dicotómica con capacidad de definir las identidades del opresor y el oprimido (capital-trabajo) como un “acto de fundación revolucionaria total” (1996, p.

37).La potencialidad política que se abre en la era contemporánea posterior a la guerra fría $\underline{42}$ es la que viene de la mano del “carácter incompleto y precario de las fronteras que constituyen” (1996, p. 37) lo social.

En EYD nos encontramos, entonces, con una concepción "radicalmente política de la sociedad” (1996, p. 180) vinculada al poder, la subversión de lógicas y la sobredeterminación de unos varios elementos por otros varios elementos: “si toda emancipación debe constituirse como poder, habrá una pluralidad de poderes -y, como consecuencia, una pluralidad de emancipaciones contingentes y parciales” (1996, p. 179). La política implica un conjunto de decisiones que dislocan-constituyen el terreno indecidible (“es decir, un terreno en el que el poder es constitutivo” (1996, p. 182)) de lo social, donde las formas sedimentadas de poder han borrado su origen contingente. La política ocupa, así, el lugar de una ontología de lo social (1996, p. 182) ${ }^{43}$.

\section{La razón populista. Dicotomía y lo popular}

La propuesta teórica de La razón populista [LRP de aquí en adelante] está en claro diálogo con la de HYES, pese a que surgen de puntos de partida diferentes. Aquí el objeto es "interroga[rse] centralmente sobre la lógica de formación de la identidades colectivas” (Laclau, 2009, p. 9), lo que llevará finalmente a un análisis en torno a "una discusión sobre populismo" (2009, p. 10). Este elemento es central para nuestra pregunta, porque el interés por este fenómeno surge de la preocupación por el rechazo que el populismo suele despertar, en el cual Laclau encuentra implícita 
una profunda “desestimación de la política toutcourt y la afirmación de que la gestión de los asuntos comunitarios corresponde a un poder administrativo cuya fuente de legitimidad es un conocimiento apropiado de lo que es la “'buena’ comunidad” (2009, p. 10). El trabajo parece estar guiado, entonces, por una pretensión de reivindicar la política (que está, desde estas primeras líneas, en una clara contigüidad con el populismo).

De forma similar a lo que detectamos en "Hacia una teoría...”, en LRP se parte de una constatación: el populismo es considerado peyorativamente por su supuesta vaguedad, su indeterminación discursiva y su calidad de "mera retórica”, así como por cierto rechazo del público al que se dirige. Frente a este diagnóstico, se argumenta que, en realidad, todos esos “defectos” son característicos de la realidad social como tal y no estrictamente del populismo. Junto a ello, y pese a que en algunos pasajes es presentado "simplemente como un modo de construir lo político” (2009, p. 11), finalmente será considerado como "la vía real para comprender algo relativo a la constitución ontológica de lo político como tal” (2009, p. 11).

En primer lugar, la concepción de lo social que atraviesa LRP es similar a la de HYES. Pero, aunque nos volvemos a encontrar con el análisis en clave retórica $\frac{44}{4}$ LRP introduce referencias psicoanalíticas que ocupan un lugar de mayor centralidad en su perspectiva sobre lo social y lo político $\underline{45}$. Pero uno de los aspectos más novedosos radica en el cambio operado en la unidad mínima de análisis: las demandas ocupan aquí el lugar principal como objetos de estudio para pensar el populismo como forma de constitución de la unidad de un grupo (2009, pp. 97-98). Estas demandas son pensadas como peticiones que pasan a ser reclamos $\frac{46}{2}$ respecto de un orden institucional establecido. En caso de que, una vez instaladas, sean automáticamente satisfechas por el orden en cuestión, pierden su condición demandante para ser absorbidas de modo diferencial (es decir, separadas de cualquier otra demanda posible). Caso contrario, si se constituye un grupo de demandas que no logran ser satisfechas, se conformará un conjunto de elementos diferentes entre sí, y a la vez equivalentes en su calidad de “insatisfechas”, que las colocaría en contra del orden vigente. El Laclau de LRP sostiene que, si en esta dispersión de demandas todas permanecen aisladas (no se articulan políticamente en torno a su condición equivalencial, no se constituyen como sujeto político), serán consideradas demandas democráticas $\frac{47}{}$. Si, por el contrario, se constituyen sobre la base de su equivalencia, en una subjetividad más amplia que las exceda en su particularidad, serán definidas como demandas populares. En el espacio de lo social -como el locus de la tensión entre las dos lógicas que se derivan de aquellos tipos de demandas (diferencial y equivalencial, respectivamente)- sólo puede emerger algún tipo de totalización si ésta, como imposible, es encarnada por una demanda/particularidad (como elementos que componen lo social). Si una identidad las incluye discursivamente en forma aislada, otorgándoles a todas el mismo peso, la totalización adquirirá un carácter institucionalista. En forma similar a lo que en HYES encontrábamos definido como gestión de la positividad social, el discurso institucionalista aparece aquí como la pura administración de las cosas, que pareciera no poder concebir identidades sociales en su dimensión colectiva. Finalmente, Laclau afirma que una construcción hegemónica populista es aquella en la que una de las demandas particulares logra expresar/encarnar la cadena equivalencial del conjunto de todas las otras demandas, excluyendo así, de modo antagónico, a otra cadena equivalencial. 
Tres de los supuestos del análisis retoman algunas de las conclusiones extraídas de HYES: a) el discurso como complejo relaciones diferenciales "constituye el terreno primario de la constitución de la objetividad como tal” (2009, p. 92); b) la articulación hegemónica -como instauración de puntos de fijación precarios de una cadena- es constitutiva de toda totalidad y de toda identidad por más fallidas e inestables que éstas sean, y por último, c) si aquella característica implica también el antagonismo, y ambas cosas suponen que toda identidad representa un bloqueo (subversión) del

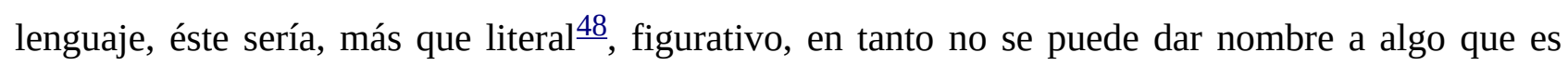
innombrable $\frac{49}{}$.

También la forma en que la lógica de la equivalencia y la lógica de la diferencia se relacionan es asimilable a la de HYES. La interrupción de la una por la otra-lo que inscribe una frontera que por su inestabilidad constitutiva está políticamente en pugna- es un fenómeno del orden de la subversión. Equivalencia y diferencia no son mutuamente excluyentes, no son identidades positivas con límites fijos. La operación de esas lógicas se da al nivel amplio de lo social (en la relación entre particularidades), pero también dentro del “cuerpo” de cada demanda $\underline{50}$. Allí, opera una suerte de “presión estructural” (2009, p. 166) donde entran en tensión aquellas lógicas (si se privilegia la condición de particularidad diferenciada quedará excluida de la cadena, para formar parte de la cual, debe privilegiar aquello que la equivale al resto $\underline{51}$ ). El caso paradigmático es el de la demanda que, en tanto punto nodal (al igual que en HYES), es parte de la cadena como una particularidad, pero no simplemente una más, sino la que presta su "cuerpo” para encarnar la totalidad de la cadena. Detengámonos en este punto y señalemos algunas cuestiones significativas.

En primer lugar, no hay nada en la demanda que indique a priori que ella será la que emerja (de la pluralidad de demandas circulantes) como el punto nodal. La emergencia es, por ende, contingente y resultante de una lucha política. Esta tesis mantiene claros puntos de similitud con las afirmaciones de HYES, NR y EYD, pero se articula aquí a un segundo aspecto del argumento, vinculado al abordaje psicoanalítico del todo social. El proceso de emergencia, desde esta óptica, implica la catexia $\underline{52}$ libidinal del significante nodal: "si una entidad se convierte en el objeto de una investidura -como estar enamorado u odiar-, la investidura pertenece necesariamente al orden del afecto”(2009, p. 142).Es -precisamente- la extensión de lógicas provenientes del psicoanálisis (como la del objetpetit $a^{\frac{53}{3}}$ ) al funcionamiento de lo social en general lo que permite concebir la investidura libidinal del punto nodal como un objeto de deseo/aversión: lo político es, entonces, un fenómeno en el que el afecto ocupa un rol privilegiado y constitutivo.

En tercer lugar, el hecho de que sea uno y no otro el significante nodal es radicalmente contingente, a raíz de que su emergencia se produce en un espacio de indecidibilidad. Pero, a la vez, esa misma posibilidad no es indiferente (2009, p. 148), ni puede ser cambiada a voluntad. Pese a los puntos de contacto que esta argumentación parece tener respecto a NR y EYD, el rol del poder como constitutivo de un espacio social desnivelado aparece desdibujado en este texto, lo que puede hacer perder complejidad analítica al abordar una situación empírica concreta.

Por último, encontramos que la investidura radical está asociada al tendencial vaciamiento del significante que, para representar una totalidad que le es inconmensurable, no puede seguir limitándose a aparecer como pura particularidad. La demanda particular no pierde nunca 
completamente dicha particularidad, pese a que su representación de la "universalidad" $\underline{4}$ es lo que prima: se vuelve cada vez más extensivamente plena al incorporar demandas a la cadena, pero para ello debe volverse intensivamente más débil, deshaciéndose de sus aspectos particulares (que podrían entrar en antagonismo con los elementos que se espera articular).Paralelamente, el otro elemento que tensiona al punto nodal (y por ende, a la cadena, o al menos su estabilidad o constitución “actual”) es la emergencia de otra cadena equivalencial alternativa; es sobre esa tensión que el significante es concebido como flotante. Esta noción apunta a la aprehensión de la lógica de funcionamiento sobre la que se realizan los desplazamientos de la frontera antagónica que divide el espacio de lo social. Si bien son diferenciados analíticamente, Laclau observa que, en los casos de estudio empíricos, los significantes tendencialmente vacíos suelen ser casi siempre flotantes $\underline{55}$ : es muy probable que la disputa política se dé entre cadenas equivalenciales que se arrogan para sí la encarnación del mismo significante, y constituyen, por ende, “contenidos” antagónicos.

En LRP la identidad que surge de la construcción hegemónica de cadenas equivalenciales es el pueblo, y ese proceso es "el acto político par excellence” (2009, p. 195), como también lo es, por lo tanto, la instauración de una frontera dicotómica. En este sentido, y si "no existe intervención política que no sea hasta cierto punto populista” (2009, p. 195), en LRP, la construcción de la frontera antagónica en un espacio político dicotomizado ya no resulta "inaceptable" $\underline{56}$ como en HYES, donde la apuesta política apuntaba a la proliferación de puntos de antagonismo, en tanto potenciales cuestionamientos de las relaciones de subordinación (en pos de la profundización de la revolución democrática). Las luchas populares dejan así de ser pensadas como meras “coyunturas específicas, resultantes de la multiplicación de efectos de equivalencia entre luchas democráticas” (Laclauy Mouffe, 2010, p. 181) $\frac{57}{y}$ pasan a ocupar un rol privilegiado.

De lo señalado en el párrafo anterior se deriva, casi directamente, que "lo político se ha convertido en sinónimo de populismo" y que "no existe ninguna intervención política que no sea hasta cierto punto populista” (2009, p. 195). Estas afirmaciones no pueden sino guiarnos a la pregunta por el lugar que se asigna a la democracia en este argumento (más aún, cuando en otros textos lo democrático y lo popular/populista detentaban estatus diferenciados). Al respecto, Laclau retoma una noción de democracia -estrechamente ligada al modelo agonístico de Chantal Mouffe (1999)-, que se distancia de la concepción liberal deliberativa moderna porque considera que excluye de su abordaje "las condiciones de existencia de un sujeto democrático" (Laclau, 2009, p. 212) $\underline{58}$, es decir, el rol crucial de las pasiones y los afectos en el aseguramiento de la lealtad a los valores democráticos. Se concluye así que una identidad democrática surgida en esas condiciones $\underline{59}$ “es prácticamente indiferenciable de lo que hemos denominado identidad popular. (...) La consecuencia es inevitable: la construcción de un pueblo es la condición sine qua non del funcionamiento democrático. Sin la producción de vacuidad no hay pueblo, no hay populismo, pero tampoco hay democracia” (2009: 213), aunque no “todos los proyectos políticos [sean] igualmente populistas” (2009: 195).

Finalmente, si las lógicas populista e institucionalista son opuestas, parece posible concebir un suerte de continuum de posibilidades entre un discurso totalmente populista y uno totalmente institucionalista, con puntos intermedios de diferentes gradaciones. 
Pero si cierta clase de equivalencia (cierta producción de un “pueblo”) es necesaria para que un discurso pueda ser considerado político (...) no estamos tratando con dos tipos diferentes de política: sólo [el discurso populista] es político [y] el [institucionalista] implica simplemente la muerte la de la política y su reabsorción por las formas sedimentadas de lo social (2009, p. 150).

Estas formas sedimentadas de lo social son aquellas en las que se ha desdibujado la huella de su institución originaria intrínsecamente política, lo que conduce a una cierta naturalización y esencialización de las identidades como estables e inmutables. Es central indicar dos puntos al respecto. Por un lado, parece posible distinguir dos facetas de lo político. Si bien aparece asociado a la institución de lo social y a su relativa estructuración en torno a articulaciones hegemónicas como un aspecto constructivo del fenómeno-, la idea de que también es justamente lo político aquello que reactiva un espacio social atravesado por la sedimentación y pone en movimiento lo estático -haciendo emerger lo novedoso-, nos remite a una característica más bien de tipo destructivo/rupturista. Por otro lado-y este es un aspecto poco explorado en este texto-, creemos que es de central relevancia preguntarnos entonces por la vinculación posible entre estos dos elementos. Revisaremos un esbozo de respuesta en las conclusiones.

\section{A modo de conclusión}

En estas líneas procuramos rastrear la forma de abordaje de lo político en cinco textos de Ernesto Laclau. En "Hacia una teoría del populismo" lo encontramos siempre en contigüidad con lo ideológico, como una categoría regional y ubicada en el "nivel” de la superestructura que está no reducida pero sí determinada en última instancia por la estructura económica. En Hegemonía y estrategia socialista, lo político es pensado en estrecha ligazón con dos nociones: la gramsciana de hegemonía y la althusseriana de sobredeterminación. Ambas son deconstruidas y rearticuladas en otra serie de elementos, dejando atrás cualquier concepción de "fundamento último" apriorístico, lo que permitiría a la articulación hegemónica expandir sus alcances como lógica política y a lo político en general, perder su regionalidad para pasar a tener el estatus de una ontología de lo social. Por su parte, Nuevas reflexiones sobre la revolución de nuestro tiempo es clave para comprender la centralidad del tiempo en lo político. Los pares conceptuales sedimentación-reactivación, espaciotiempo y lo social - lo político se fundan en la condición dislocada e indecidible de la estructura y se caracterizan por relaciones de mutua imbricación. Por su parte, Emancipación y diferencia propone colocar en el centro de la escena a los significantes vacíos como productos de la operación política hegemónica, en un espacio social atravesado por relaciones de poder que lo configuran como constitutivamente desnivelado. Por último, en La razón populista señalamos algunas coincidencias con el planteo de HYES, pero destacamosla centralidad que la dimensión afectiva cobra en la constitución del vínculo hegemónico. En este marco, la lógica hegemónica se asocia a la emergencia del sujeto popular (el pueblo) relacionado fundamentalmente (y en divergencia a la multiplicidad de antagonismos de HYES) a la dicotomización del espacio social. Aquí, populismo y lo político pasan a ser casi sinónimos, en tanto la construcción de aquel sujeto pueblo deviene el acto político por excelencia.

HYES, NR, EYD y LRP comparten la perspectiva de la radical apertura de lo social y su constitución siempre política, desechando así el meollo del argumento de "Hacia una teoría del 
populismo", es decir, la condición de clase del principio articulador de toda identidad popular democrática $\underline{60}$. Pero el recorrido que planteamos dejó entrever, además, que en LRP se alude a la noción de sobredeterminación en contados pasajes, por lo que parece haber perdido gran parte de su centralidad y potencialidad explicativa. Y esto no deja de resultar llamativo porque fue precisamente la deconstrucción de este concepto althusseriano la que en HYES había permitido aprehender el núcleo de la propuesta teórica, es decir, la apertura de lo social y su indecidibilidad estructural. Un solo pasaje dialoga, en este sentido, casi directamente con HYES: "Un capitalismo globalizado crea una miríada de puntos de ruptura y antagonismos (...), y es sólo una sobredeterminación de esta pluralidad antagónica la que puede crear sujetos anticapitalistas (...)” (Laclau, 2009, p. 189). Junto con la subversión, la sobredeterminación aparece (en estas líneas citadas, en HYES y, en parte, en NR) como un elemento clave para pensar el descentramiento del terreno de lo social y, por ende, de su constitución política, por lo que su potencialidad a nivel teórico y de praxis política debe ser revalorada. Y esto es así porque estas nociones son las que nos permiten pensar la relativa estructuración del espacio social, ya no referida a un antagonismo (pre)determinado y (apriorísticamente) privilegiado con influencia unidireccional sobre otro elemento, sino marcada por la complejidad que ofrece la multiplicidad de elementos (sobre)determinantes y sus interrelaciones descriptas en términos de reenvíos simbólicos. Este último aspecto es el que, de la mano de los procesos de subversión, concibe la mutua imbricación de unos elementos en y con otros, la “contaminación” y la "hibridización” (Daín, 2014; Aboy Carlés, 2001) resultantes de la copresencia/cohabitación de una multiplicidad de elementos, en un marco de pluralismo $\underline{61}$.

Como características de todo proceso de significación, la sobredeterminación y la subversión $\underline{62}$ constituyen la dinámica de las relaciones entre los más diversos elementos que surcan lo social. También se gestan (como vimos más arriba) montados entre el interior/exterior de las unidades significativas, las cuales remiten a la tensión entre las lógicas de la equivalencia y la diferencia y, por ende, al problema político por excelencia que constituye la emergencia de significantes tendencialmente vacíos/flotantes, y la concomitante constitución de las identidades políticas. Proponemos retomar, entonces, las propuestas de Emancipación y diferencia y Nuevas reflexiones $\underline{63}$ en la siguiente clave de lectura. Si bien la emergencia de un punto nodal es contingente y no hay nada en su "contenido" que (pre)determine que sea ése y no otro el que emerja como tal, es central para comprender las características de ese proceso, no olvidar que se gesta en un espacio social con un carácter intrínsecamente desnivelado (Laclau, 1996, p. 81), dislocado y atravesado por relaciones de poder sedimentadas que condicionan -nunca totalmente- todo proceso de emergencia (reactivación). Lo social está surcado por una multiplicidad de puntos de concentración de poder heterogéneos, resultantes ellos también de luchas políticas pretéritas, que permiten concluir que, en un momento histórico específico, no todos los elementos/luchas/significantes que surcan lo social tienen exactamente la misma capacidad de encarnar la "totalidad". Y junto con las relaciones de poder (exclusión-subordinación) que se desarrollan en el magma social -y que son centrales para analizar una situación histórica de emergencia de un punto nodal y la construcción de una cierta configuración hegemónica-, encontramos la ya referida dimensión afectiva. Esta última, creemos, es la noción clave del aporte de La razón populista al pensamiento de lo político $\underline{64}$. 
En otro de sus escritos (vinculado a la cuestión de la decisión como momento disruptivo parangonable al de la emergencia del punto nodal), Laclau (2011) sostiene que

...el sujeto que toma la decisión es sólo parcialmente un sujeto; él es también un fondo de prácticas sedimentadas organizadoras de un marco normativo que opera como una limitación del horizonte de opciones. Pero si ese fondo persiste a través de la contaminación del momento de la decisión, diría también que la decisión persiste a través de la subversión de ese fondo. Esto significa que la construcción de un fondo normativo comunitario (que es una operación política y de ninguna manera simplemente ética) tiene lugar a través de la limitación de lo ético por lo normativo y de la subversión de lo normativo por lo ético (2011, p. 91).

En este sentido, el conjunto de prácticas sedimentadas (lo institucionalizado en LRP) resultantes de otras prácticas políticas previas y del surgimiento pretérito de otras cadenas equivalenciales opera como un fondo $\frac{65}{5}$ sobredeterminante. Si la nominación tiene un efecto retroactivo (del presente sobre el pasado), no es menos cierto que ella se produce en un espacio siempre-ya semiestructurado que tiene, a su vez, efectos sobre la nominación misma (emergencia del punto nodal) y sobre la cadena equivalencial que constituirá a la identidad política hegemónica. De la misma manera que interioridad y exterioridad quedan sujetas al borramiento de sus límites como entidades ontológicamente diferenciadas y diferenciables, pasado y presente deben sufrir un proceso similar: la sobredeterminación no puede ser pensada como una categoría regional limitada a una lógica espacial, sino que exige ser extendida al pensamiento de toda temporalidad, para resignificara sí tanto lo social como lo político que lo instituye.

Es también primordial reforzar la concepción de la vacuidad del significante nodal como constitutivamente tendencial, caracterización que -en cierta forma- se ve desdibujada, por ejemplo, en La razón populista. No se debe perder de vista el hecho de que la subversión de la lógica diferencial, que supone el privilegio del momento equivalencial para el surgimiento del SV que constituye la cadena, es un proceso que erradica "la relevancia de toda localización diferencial” (Laclau, 1996, p. 81) sólo tendencialmente. O, lo que es lo mismo, los significantes sólo pueden ser tendencialmente vacíos y la particularidad se erige como un resto que sobredetermina a toda la cadena, haciendo que no cualquier demanda/lucha pueda ser incorporada a la cadena, pero que también tensiona constantemente su continuidad como punto nodal (si es que esas particularidades, en vez de ser excluidas, logran destronar al punto nodal que les impedía incorporarse, resignificando toda la cadena).

Para que estas afirmaciones alcancen toda la potencialidad que creemos tienen, debemos -bien que sosteniendo la diferencia analítica- abordar todo significante tendencialmente vacío en su condición de flotante (porque, como bien sostiene Laclau en algunos pasajes de LRP, éste siempre es el caso en los procesos históricos concretos). Los significantes flotantes se "montan” sobre dos cadenas equivalenciales en disputa, pero creemos que, si como se afirma en HYES y NR (y en menor medida en LRP), las sociedades contemporáneas están marcadas por la multiplicidad de relaciones de subordinación potencialmente antagónicas, nada indica que no podamos concebir a aquellos significantes como tensionados por una mayor cantidad de cadenas equivalenciales, cuyos elementos no se enfrentarían tampoco punto a punto, uno a uno, como en una suerte de espejo. Las 
relaciones sobredeterminadas y subvertidas entre las cadenas equivalenciales permiten pensar “fronteras extremadamente permeables" (Aboy Carlés, 2012: 18) e identidades que adoptan un formato de manchas superpuestas (Aboy Carlés, 2012), con elementos que se solapan en su articulación a cada una de las múltiples cadenas precariamente articuladas. El norte debe ser pensar la posibilidad de la organización de un espacio social no siempre dicotomizado, sino complejo, multidimensional y plural, tanto espacial como temporalmente, y constitutivamente atravesado por relaciones de poder.

\section{Notas}

1 Esta forma de abordaje de los textos de “un autor” no sólo retoma la propuesta de Foucault (1969) al respecto, sino también la de Laclau mismo cuando alude, por ejemplo, a "el Wittgenstein del Tractatus”(Laclau, 2000, pág. 78), dejando entrever la idea de que cada texto de Wittgenstein se puede pensar como perteneciente a un Wittgenstein distinto, y ya no como si hubiese un Wittgenstein (cuya esencia se "desenvolvería” a lo largo de una obra como totalidad cerrada). Asimismo, y deconstruyendo de forma similar las nociones de "texto" o "libro" -en su pretendida unidad-, podríamos encontrar las huellas de “más de un Wittgenstein” dentro del mismo texto.

$\underline{2}$ Retomamos aquí la noción de polemicidadschmittiana, particularmente productiva para pensar el estatuto de lo político: “(...) todos los conceptos, nociones y vocablos políticos tienen un sentido polémico (...)”, a la vez que “[dicho] carácter polémico impregna también la acepción usual de los términos ‘político’ y ‘apolítico’”(Schmitt, 2015, págs. 32-33). No supone solamente una cuestión teórica, sino también una forma específica de concepción de la lucha política y, como veremos más adelante, de lo social y las relaciones que se enmarcan.

$\underline{3}$ En Política e ideología en la teoría marxista. Capitalismo, fascismo, populismo.

$\underline{4}$ Parte I del libro que lleva el mismo nombre que este apartado.

$\underline{5}$ Tomamos esa denominación de Daín(2011; 2014).

$\underline{6}$ El foco se colocaría así en el proceso de emergencia de un significante nodal como tal y no sólo en la identificación del mismo en una coyuntura dada. Es de radical importancia destacar que esta operación sólo puede realizarse a posteriori del proceso: la reconstrucción analítica de la emergencia de un significante nodal y de estructuración de una formación discursiva histórica específica es una operación que no sólo identifica, sino que también otorga sentidos en forma retroactiva.

$\underline{7}$ La noción de nivel remite a una concepción que entiende al espacio social como conformado por regiones teóricamente delimitables y empíricamente delimitadas. El propio Althusser (en Ideologíay aparatos ideológicos del Estado) intentó salvaguardar esta metáfora arguyendo que era solamente de carácter espacial y que implicaba que "los pisos superiores no podrían sostenerse (en el aire) por sí solos si no se apoyaran precisamente sobre su base” (2008, p. 17). Las contradicciones en las que recae Althusser en su intento de romper con el reduccionismo economicista de ciertas lecturas de los textos de Marx (sobre todo de su "Prólogo a la Contribución 
a la crítica de la economía política”) no son muy distintas a algunas que aquí señalamos.

$\underline{8}$ Retomamos aquí lo señalado en la nota 1. Es probable que la expresión "el Laclau de tal texto" pueda herir la pupila del lector. En el hecho de que "suene" casi grotesco se hace patente la eficacia del discurso respecto a la constitución performativa de eso que llamamos "identidad”. Esta noción es fundamental en la construcción de las de "autor”, su "obra” y cada uno de sus “textos”, en tanto requieren entender la identidad como algo idéntico/igual a sí mismo en el tiempo, garantizada por un fundamento último esencial (en relación a esto podemos pensar en casos como el "la obra" de Marx, para la cual es común referirse a la existencia de un Marx "maduro”, frente a otro "joven”, y se busca en el "joven” las huellas del "maduro" que "ya estaban” previamente en él, como una esencia en desenvolvimiento). Creemos que pensar que no hay un autor de una obra permite encarar lecturas que apunten a identificar potencialidades y también problemáticas; eludir abordajes en clave evolutiva de la obra habilita la detección de diferentes aristas de un mismo problema entre los escritos y en el interior de cada uno (sin atentar, sin embargo, contra abordajes comparativos). Hecha esta advertencia, se notará que a lo largo de estas líneas se aludirá sin más a "Laclau”, a raíz de lo complejo que resulta desprenderse definitivamente de la noción de autor y con el objeto de hacer más amena la lectura.

$\underline{9} \mathrm{Al}$ respecto resulta relevante señalar que pese a que estos "contenidos” aparecen asociados a algo del orden de lo discursivo, no se explicita qué se entiende por tal y cuáles son sus alcances.

10 En forma similar, para Gramsci(2008) es el elemento de clase (e.g. intelectuales orgánicos) el que brinda coherencia y sistematicidad a una cierta concepción del mundo o ideología.

11 Realizamos esta afirmación con relativa rapidez y reconocemos que debe ser profundizada, lo que excede los objetivos de este texto.

12 Esta noción no aparece en este texto; recurrir a ella -aunque resulte artificial en este contextopermite señalar las potencialidades de este desarrollo teórico, no teniendo que acudir a significantes como existencia o ser.

13 Este razonamiento aparece con claridad en su pregunta por el nacionalismo: “en sí mismo no tiene ninguna connotación clasista. Esta última sólo procede de su articulación específica a otros elementos ideológicos” (laclau, 1986, p. 189).

14 Por eso las clases medias, al no participar en las relaciones de producción fundamentales de la sociedad, no tienen principio articulador propio, quedando su ideología siempre a merced de las de las otras clases (fundamentales).

$\underline{15}$ Llegado este punto es interesante preguntarse cómo algo que es prioritario se ubica, a su vez, en una última instancia. No creemos que ambas caracterizaciones sean a priori incompatibles, pero sí que su convivencia no es clarificada en el texto.

16 De forma similar, "las tradiciones populares no constituyen discursos coherentes y organizados, sino puramente elementos que sólo existen articulados discursos de clase” (Laclau, 1986, p. 195).

17 De clase o en relación al bloque de poder, como el caso del populismo de clase dominante.

$\underline{18}$ Es decir, por ejemplo, el conjunto de instituciones y prácticas del sistema político de partidos, en 
tanto gestión o administración de lo ya instituido.

19 Podríamos decir que la nueva forma de abordaje de estas nociones implica una rearticulación de las mismas en una cadena distinta, de forma que las "identidades" de todos los elementos se ve modificada. Laclau y Mouffe parecen detectar un mecanismo de este orden al subrayar que en el desarrollo de su argumento se analizan conceptos que ya estaban presentes en otros discursos teóricos (como el de Althusser o el de Gramsci), "pero inhibidos en su desarrollo por su coexistencia [(articulación)] con categorías básicas del discurso esencialista” (Laclau y Mouffe, 2010, p. 133). Al desechar esas categorías, el carácter de la totalidad también se ve modificado, es decir, pierde su componente esencialista.

$\underline{20}$ Se indica, además, que la noción de punto nodal detenta un estatuto cercano al de los point de capitonlacanianos (Laclau y Mouffe, 2010, p. 152).

21 Allí encontrábamos que la retórica era desvalorizada como "mera retórica” y se oponía podemos concluir- a un plano "más real”. En cierto sentido, detrás de esa afirmación, se hallaba una disociación entre el plano de la palabra (la retórica) y el de la materialidad (de la base real, vinculada al componente económico y, por ende, de clase), y el otorgamiento de una clara preeminencia al segundo por sobre el primero.

$\underline{22}$ El vínculo entre los componentes de estos pares conceptuales puede entenderse en la misma forma que lo hace Derrida(1977), en tanto irreductibles a una dialéctica y, por ende, indecidibles: “(...) el hymen no es ni la confusión ni la distinción, ni la identidad ni la diferencia, ni la consumación ni la virginidad, ni el velo ni el desvelamiento, ni el dentro ni el afuera, etc.; el grama no es ni un significante ni un significado, ni un signo ni una cosa, ni una presencia ni una ausencia, ni una posición ni una negación, etc.; el espaciamiento, no es ni el espacio ni el tiempo [...] Ni/ ni, es a la vez o bien o bien; la marca también es el límite marginal, la mancha, etc...” (1977, p. 55).

$\underline{23}$ Es interesante retomar las definiciones de la RAE para subversión e inversión. Ambos procesos implican “dar vuelta” algo, pero mientras el primero implica que esto se hace desde abajo (subversión) hacia arriba (o viceversa), el segundo supone que el proceso se realiza desde adentro (inversión) hacia afuera (o viceversa). Resulta por demás paradójico el retorno a la alusión topológica de arriba-abajo que el uso de subversión implica etimológicamente, cuando inversión (tradicionalmente asociada a aquel sentido y a la metáfora marxiana del edificio) parecería mucho más apropiado.

24 De algún modo, esta forma de pensar lo social no admite hablar de que "algo es”. Más que decir que "la objetividad es”, sería más apropiado hablar de que "hay objetividad”. Este ejemplo alude a la experiencia de los límites de la objetividad, en tanto encontramos ciertos problemas al querer "hablar" de "los objetos" de una forma distinta a la que estamos acostumbrados.

$\underline{25}$ Laclau y Mouffe señalan en la nota 40 la asimilación por parte de Laclau en otros textos (refieren a otro texto contemporáneo de “Hacia...”) entre antagonismo y contradicción.

$\underline{26}$ La itálica es de los autores y creemos que permite resaltar la calidad de proceso más que de hecho consumado de la objetivación (vs. objetividad).

$\underline{27}$ El vocablo original en inglés es foundational, y su traducción literal es fundacional. Aparece 
también en un pasaje relacionado a la naturaleza del poder que "no es nunca fundacional” (2010, p. 186) y parece aludir a esta misma lógica de la determinación por un punto privilegiado del espacio social, porque se señala que no debe buscarse en una clase o sector dominante como centro de una formación hegemónica. Habría que preguntarse qué vínculo tiene con la expresión fundamental que parece más apropiada; sin embargo, el aspecto está poco desarrollado.

$\underline{28}$ Es preciso aclarar que esta politización es potencial: si todo fuera político, nada sería específicamente político. El sentido de esta afirmación se desbroza en las líneas subsiguientes.

$\underline{29}$ En este punto, los autores no se distancian demasiado de la definición de lo político de Schmitt (2015).

30 Lo que no implica que este escrito sea el único ni el primero que sostiene esta distinción conceptual. Para un detalle de la génesis de la noción de diferencia política ver Marchart(2009).

$\underline{31}$ Nos permitimos prescindir aquí de la definición de lo político como ontología de lo social. Si bien lo desarrollado en este párrafo va en una línea similar, esa definición corresponde al Prefacio a la Segunda edición en el español del año 2002, por lo que no corresponde al texto original sino a una relectura posterior por parte de los autores.

$\underline{32}$ Aunque, por supuesto, nunca debemos perder de vista que toda articulación es siempre una rearticulación; subrayamos la distinción analítica a los efectos de argumentar nuestra tesis.

33 Abordaremos específicamente el capítulo que lleva el mismo nombre que el libro ("Nuevas reflexiones sobre la revolución de nuestro tiempo). De aquí en más, NR.

$\underline{34}$ Esto no implica que no se presenten pasajes que abordar la articulación de los significantes en torno a uno nodal. Sin embargo, no es allí a donde se orienta puntualmente el texto.

35 La noción indecidibilidad remite a una característica que según Laclau -retomando a Derrida- es constitutiva de todo orden. La condición indecidible de la estructura supone que "si dos grupos diferentes han optado por decisiones distintas, como no hay fundamento racional último para decidir entre ambas, la relación entre ambos grupos será una relación de antagonismo y de poder” (Laclau, 2000, p. 48). Por tanto, la indecidibilidad caracteriza tanto al orden (estructura) -relación interior/exterior- como a las relaciones en el interior de ella. Asimismo, se vincula intrínsecamente con las relaciones de poder en las que se funda una decisión, la cual es arbitraria y no se liga “de modo necesario a un motivo racional; [lo que] no significa que (...) no sea razonable -es decir, que un conjunto acumulado de motivos, ninguno de los cuales tiene valor de un fundamento apodíctico, no la hagan preferible a otras decisiones” (2000, p. 47) [itálicas en el original]. Es esta condición indecidible de la estructura la que signa la constitutiva contingencia del proceso de emergencia de toda demanda/punto nodal (porque no hay una racionalidad intrínseca y esencial a la estructura que determine absolutamente la emergencia de una u otra demanda como nodal en la articulación de una cadena dada).

36 Como tendremos oportunidad de revisar luego, las nociones de falla y lo traumático remiten a cierto lenguaje psicoanalítico que será clave en La razón populista. Se recurre, además, a ejemplos explicativos como el juego Fort/Da, analizado por Freud como instancia traumática.

37 Derrida (1994) aportará la noción de iteración para abordar la repetición no exactamente igual a 
sí misma, que sólo puede producirse gracias a la mediación del tiempo.

$\underline{38}$ En este sentido, la dislocación es "la forma misma de la temporalidad" (2000, p. 58).

$\underline{39}$ Por tanto, todo origen político comporta una dimensión violenta constitutiva.

40 Como señala Saussure (1945) cada unidad comporta una posición relativa en el sistema de valores diferenciales (lengua), dada por su vínculo negativo con otras unidades que están en la misma condición.

\section{$\underline{41}$ Ver nota 24.}

42 Recordemos que este acotamiento temporal también estaba presente HYES.

$\underline{43}$ En este sentido, se acerca al polo de "lo político" como lo definimos en el apartado dedicado a HYES y manteniendo la distinción ya referida de Marchart (2009). Mantenemos la política respetando el léxico del texto (que se hace presente en el título mismo del capítulo).

44 Dicha clave supone que los mecanismos retóricos son asimilables a las lógicas de funcionamiento de lo social, porque ambos comparten su condición de ser órdenes significantes.

45 Aludimos a los conceptos de objetpetit a y las lógicas de investidura libidinal, que complementan a la del point de capiton, presente en HYES.

$\underline{46}$ La petición pareciera realizarse desde un "exterior”, mientras que reclamo parece aludir a una cierta pertenencia (que permite reclamar algo que “corresponde” y no "pedir” algo que podría no ser así).

47 Laclau dedica algunas líneas a aclarar la calificación de las primeras demandas (las que no logran constituir una “subjetividad más amplia”, es decir, política) como democráticas. Si, como veremos más adelante, lo “popular”/populista queda profundamente imbricado con lo político, el lugar en que quedan aquéllas en esta concepción es, al menos, problemático. Porque si bien Laclau afirma que el calificativo no tiene que ver con el régimen democrático en sí (Laclau, 2009, p. 158), las demandas de este tipo quedan asociadas a un orden administrativo-institucional que tendría un déficit en su dimensión política. No podemos (ni intentamos) reponer la intención originaria de la escritura (“qué quiso decir el autor”), pero tampoco podemos dejar de señalar que, en un espacio teórico donde el discurso y las palabras cobran una importancia radical (y política), la articulación de lo "democrático" con lo administrativo/no político es profundamente polémica (e incluso, provocadora). Resulta significativa, además, la persistencia de la distinción entre lo popular y lo democrático, cuyo divorcio parece inevitable HYES, EYD y LRP. Esta continuidad aparece, sin embargo, solapada por la valoración diferencial en la que se inscribe el binomio popular/democrático en cada texto.

$\underline{48}$ No olvidemos que dijimos que toda literalidad es subvertida.

$\underline{49}$ En otras palabras, si todo lenguaje (discurso) es un sistema de diferencias, todo lo que no sea una diferencia es insimbolizable (“no se puede decir”). Y si el límite de toda formación (incluso del discurso mismo) se da en el espacio de una tensión irresoluble entre las lógicas de la diferencia y de la equivalencia, entre positividad y negatividad, significa que no es ninguna de las dos cosas (o es la subversión mutua). Por lo que si no es estrictamente una diferencia más (la frontera es antagónica) 
es insimbolizable "literalmente", conceptualmente; sólo puede ser representado en el orden de lo catacrético (entendemos por catacresis el dar a una palabra un sentido traslativo para denominar algo que carece de nombre especial).

$\underline{50}$ Remitimos a la expresión gráfica como círculo dividido en dos semicírculos.

$\underline{51}$ Que no es nunca algo positivo, sino la oposición frente a otra cosa, es decir, una negatividad.

$\underline{52}$ Esta noción excede ampliamente el campo en que este trabajo se inserta, pero podemos referir como breve definición que se entiende por catexia a la descarga de energía psíquica que supone una acumulación de libido en un elemento dado.

$\underline{53}$ Como señalamos en la nota precedente, este aspecto desborda los límites del escrito y su enfoque. Remitimos a Stavrakakis (2007)para ahondar sobre el punto.

$\underline{54}$ Entre comillas porque, por supuesto, no es totalmente tal.

$\underline{55}$ Retomaremos en las conclusiones las implicancias de esto para los análisis empíricos.

56 Esta cita remite al pasaje en que Laclau y Mouffe cuestionan la concepción gramsciana de un espacio político dicotómicamente dividido (2010, p. 181). Los pensadores afirman allí que una concepción dicotómica de este tipo es "inaceptable" en un contexto en que "la proliferación de espacios políticos y la complejidad y dificultad de su articulación son unas de las características centrales de las formaciones sociales del capitalismo avanzado” (2010, p. 181).

$\underline{57}$ Lo que no está presente en LRP es esa concepción del populismo como “coyuntura específica”, porque de alguna forma la segunda parte del razonamiento sí está allí, ya que en algunos pasajes el "pueblo" es entendido en términos de "articulación entre una pluralidad de puntos de ruptura" (2009, p. 155).

58 Según los autores, esta democracia liberal concibe la posibilidad del establecimiento de un consenso racional por parte de individuos anteriores a la sociedad (sujeto cartesiano) y portadores de derechos individuales.

59 Estas implican un espacio social donde se concibe la unidad de sujetos sociales más allá de un orden puramente conceptual (es decir, donde las relaciones son indecidibles), en el que no existe una racionalidad a priori que garantice dicha unidad y ni la articulación de las demandas en torno a un centro predeterminado y en donde el rol del afecto es neurálgico en la constitución de las identidades.

60 Es probable que se pueda atribuir a esta característica el origen de los cuestionamientos que ha recibido La razón populista en torno a cierto exceso de formalismo y cierto "déficit normativo" (Fair, 2014). Sin embargo, no podemos dejar de notar que también Nuevas reflexiones incurre en cierto formalismo de la teoría al buscar articular la relativización de los valores éticos, políticos e intelectuales de la modernidad con el sostenimiento de una política radicalizada o progresiva (Laclau, 2000), vinculada al socialismo.

$\underline{61}$ No son pocos los trabajos que abordan las limitaciones para pensar el pluralismo político (asociado a esta pluralidad constitutiva de lo social) en ciertos textos de Ernesto Laclau. (Cf. (Aboy Carlés, 2007) y (Suárez, 2015).) El foco de los cuestionamientos se coloca -usualmente- en La 
razón populista, dejando de lado sus vínculos con textos como “Hacia una teoría del populismo”.

$\underline{62}$ Sostenemos que deberían considerarse un par explicativo inescindible.

$\underline{63}$ La radicalidad con la que estas afirmaciones aparecen en estos textos no está presente en los otros aquí referidos y es por ello que reforzamos este punto.

64 Debemos recordar aquí que el foco de este escrito es la constitución de las identidades políticas en general, y no el populismo en particular, como una entre otras formas de hegemonía (Melo, 2011).

65 El término fondo no pretende aludir a una ubicación espacial (por debajo o por atrás). Probablemente sea necesario seguir trabajando sobre este problema para encontrar expresiones más pertinentes (pese a lo imposible de encarar una tarea de encontrar un significante "adecuado" a un significado que se construye en y por esa nominación).

\section{Bibliografía}

Aboy Carlés, G. (2001). Las dos fronteras de la democracia argentina: la reformulación de las identidades políticas de Alfonsín a Menem. Rosario: Homo Sapiens.

Aboy Carlés, G. (2007). La democratización beligerante del populismo. Debate. Revista de la Asamblea Nacional de Panamá, 47-58.

Aboy Carlés, G. (2012). "De lo popular a lo populista o el incierto devenir de la plebs. Para una crítica del neorromanticismo posfundacional”. VI Congreso Latinoamericano de Ciencia Política (ALACIP). Quito.

Althusser, L. (2008). Ideología y aparatos ideológicos de Estado. Buenos Aires: Nueva Visión.

Daín, A. (2011). Marx, Althusser y Derrida. La sobredeterminación como suplemento. Astrolabio (6).

Daín, A. (2014). La lógica de la sobredeterminación: hacia una radicalización del análisis político. Pensamento Plural, 91-109.

Derrida, J. (1977). Posiciones. Valencia: Pre-Textos.

Derrida, J. (1994). Firma, acontecimiento, contexto. En J. Derrida, Márgenes de la filosofía. Madrid: Cátedra.

Fair, H. (2014). Lo ético-político en las democracias contemporáneas. Reflexiones críticas en torno al déficit normativo en la teoría de la hegemonía de Ernesto Laclau. Revista CS(13).

Foucault, M. (1969). ¿Qué es un autor? (Conferencia del 22/02/1969). Bulletin de la Societé française de philosophie (3 (julio-septiembre 1969)), 73-104.

Gramsci, A. (2008). La filosofía de Benedetto Croce y el materialismo histórico. Buenos Aires : Nueva Visión.

Laclau, E. (1986). Hacia una teoría del populismo. En E. Laclau, Política e ideología en la teoría marxista. Capitalismo, fascismo, populismo. Madrid: Siglo XXI. 
Laclau, E. (1996). Emancipación y diferencia. Buenos Aires: Ariel.

Laclau, E. (2000). Parte I. Nuevas reflexiones sobre la revolución de nuestro tiempo. En E. Laclau, Nuevas reflexiones sobre la revolución de nuestro tiempo. Buenos Aires: Nueva Visión.

Laclau, E. (2000). Nuevas reflexiones sobre la revolución de nuestro tiempo. Buenos Aires: Nueva Visión.

Laclau, E. (2009). La razón populista. Buenos Aires: Fondo de Cultura Económica.

Laclau, E. (2011). Identidad y hegemonía: el rol de la universalidad en la constitución de las lógicas políticas. En E. Laclau, J. Butler, \& S. Zizek, Contingencia, hegemonía, universalidad. Diálogos contemporáneos en la izquierda. Buenos Aires: Fondo de Cultural Económica.

Laclau, E. y Mouffe, C. (2010). Hegemonía y estrategia socialista. Hacia una radicalización de la democracia. Buenos Aires: FCE.

Marchart, O. (2009). El pensamiento político posfundacional. La diferencia política en Nancy, Lefort, Badiou y Laclau. Buenos Aires: FCE. 